\title{
Imunocards: aprendendo as defesas do organismo jogando
}

\author{
Immunocards: learning the organism's defenses by playing \\ Inmunocards: aprendiendo las defensas del organismo jugando
}

Maurício de Almeida Vale Filho

ORCID: https://orcid.org/0000-0002-4489-9623 Universidade do Estado do Rio Grande do Norte, Brasil E-mail: mavalefilho@hotmail.com

Pablo de Castro Santos

ORCID: https://orcid.org/0000-0003-0081-9609 Universidade do Estado do Rio Grande do Norte, Brasil E-mail: pablocastro@uern.br

Allyssandra Maria Lima Rodrigues Maia

ORCID: https://orcid.org/0000-0001-6590-5095 Universidade do Estado do Rio Grande do Norte, Brasil E-mail: allyssandramr@hotmail.com

\begin{abstract}
Resumo
O estudo da Imunologia revela a importância de se conhecer a atuação do Sistema Imunológico nas defesas do organismo e sua habilidade de resposta à ação de substâncias imuno estimulantes e/ou invasão de microrganismos do ambiente. Esse conteúdo deve ser ministrado na disciplina de Biologia, sobretudo por entender-se, que na educação básica, a formação conceitual e o estabelecimento de relações entre estes conceitos são primordiais para a formação do indivíduo. Nessa perspectiva, o trabalho teve como objetivo desenvolver um jogo de cartas do tipo baralho, de caráter lúdico, educativo e investigativo e inseri-lo no contexto do ensino da Imunologia para alunos do ensino médio, de uma escola estadual do município de Russas-CE. Metodologias diversificadas como o uso de jogos tem elevada aceitação dentre os estudantes, e estes, mediante a atividade, demonstram melhor compreensão global dos temas tratados na disciplina. A pesquisa foi realizada com base no método interpretativo em consonância com a abordagem quali-quantitativa. A análise interpretativa dos dados qualitativos revelaram uma boa percepção dos estudantes acerca do tema proposto, logo, os mesmos apresentaram conhecimentos prévios importantes para uma boa compreensão do conteúdo nas aulas de Biologia. Os resultados quantitativos por sua vez evidenciaram que o jogo IMUNOCARDS auxiliou na compreensão do estudo da Imunologia, bem como, facilitou a aquisição de informações e a produção de novos conhecimentos. Os dados permitiram ainda, perceber que o jogo se mostrou uma ferramenta criativa, agradável, atraente, lúdica e inovadora no ensino de Biologia.
\end{abstract}

Palavras-chave: Ensino; Imunologia; Jogo didático; Lúdico.

\begin{abstract}
The study of Immunology reveals the importance of knowing the role of the Immune System in the body's defenses and its ability to respond to the action of immune stimulating substances and/or invasion of microorganisms from the environment. This content should be taught in Biology subject, mainly because it is understood that in basic education, conceptual formation and the establishment of relationships between these concepts are essential for the formation of the individual. In that perspective, the objective of the work was to develop a card game, of a ludic, educational and investigative character and to insert it in the context of teaching immunology to middle school students, from a state school in the city of Russas-CE. Diversified methodologies such as the use of games have increased acceptance among students, and these, through the activity, demonstrate a better global understanding of the subjects covered in the discipline. The research was carried out based on the interpretative method in line with the qualitative and quantitative approach. The interpretative analysis of the data revealed a good perception of the students about the proposed theme, therefore, they presented important knowledge for the good understanding of the content in Biology classes. The quantitative results in turn showed that the IMUNOCARDS game helped in understanding the study of Immunology, as well as facilitating the acquisition of information and production of new knowledge. The data also allowed us to realize that the game proved to be a creative, pleasant, attractive, ludic and innovative tool in the teaching of Biology.
\end{abstract}

Keywords: Teaching; Immunology; Educational game; Ludic. 
Research, Society and Development, v. 11, n. 2, e44211226020, 2022

(CC BY 4.0) | ISSN 2525-3409 | DOI: http://dx.doi.org/10.33448/rsd-v11i2.26020

\begin{abstract}
Resumen
El estudio de la Inmunología revela la importancia de conocer el papel del Sistema Inmunológico en las defensas del organismo y su capacidad de respuesta ante la acción de sustancias inmunoestimulantes y/o invasión de microorganismos del medio ambiente. Este contenido debe ser impartido en la disciplina de Biología, principalmente porque se entiende que en la educación básica, la formación conceptual y el establecimiento de relaciones entre estos conceptos son fundamentales para la formación del individuo. En esa perspectiva, el trabajo tuvo como objetivo desarrollar un juego de naipes, educativo e investigativo, e insertarlo en el contexto de enseñanza de Inmunología para estudiantes de enseñanza media, en una escuela pública del municipio de Russas-CE. Metodologías diversificadas como el uso de juegos tienen alta aceptación entre los estudiantes, y estos, a través de la actividad, demuestran una mejor comprensión global de los temas tratados en la disciplina. La investigación se llevó a cabo con base en el método interpretativo en línea con el enfoque cuali-cuantitativo. El análisis interpretativo de los datos cualitativos reveló una buena percepción de los estudiantes sobre el tema propuesto, por lo tanto, presentaron conocimientos previos importantes para una buena comprensión de los contenidos en las clases de Biología. Los resultados cuantitativos, a su vez, mostraron que el juego IMMUNOCARDS ayudó en la comprensión del estudio de la Inmunología, así como facilitó la adquisición de información y la producción de nuevos conocimientos. Los datos también permitieron percibir que el juego demostró ser una herramienta creativa, amena, atractiva, lúdica e innovadora en la enseñanza de la Biología.
\end{abstract}

Palabras clave: Enseñanza; Inmunologia; Juego didáctico; Lúdico.

\title{
1. Introdução
}

É sabido que no meio em que vivemos, no ar que respiramos, bem como nos alimentos e na água que ingerimos, há quase sempre a presença de microrganismos infecciosos, como: vírus, bactérias, protozoários, fungos ou vermes, capazes de penetrarem no nosso organismo e provocarem algum tipo de desordem fisiológica. Essas doenças clássicas também conhecidas como viroses, infecções bacterianas ou ocasionadas por protozoários e fungos e as verminoses, são adquiridas principalmente de forma direta em função de maus hábitos alimentares ou de higiene pessoal e podem ainda serem repassadas para outras pessoas, o que se configura como um problema de saúde pública. Todavia, nem sempre somos acometidos por essas doenças, o que nos permite concluir que na maioria das vezes estamos imunes as mesmas (Murphy, 2014).

O termo Imunidade se deriva do Latim Immunitas, usado na Roma Antiga para fazer referência as isenções de taxas oferecidas aos Senadores Romanos. Atualmente essa nomenclatura representa também proteção a doenças, mais especificamente doenças infecciosas causadas por seres microscópicos que atingem o organismo humano, sendo a ação do sistema imune vista com o fito de manter o organismo isento, protegido e/ou defendido de substâncias estranhas e/ou de invasão causada por outros organismos provenientes do ambiente (Forte, 2011).

A Imunologia, é o ramo da Biologia responsável pelo estudo da Imunidade, ou seja, das reações de defesa do organismo que conferem aos mesmos resistência as doenças (Abbas et al., 2015). Seus estudos foram iniciados ainda no século XVIII, quando o Inglês Edward Jenner (1749 - 1823) observou que a doença da Varíola Bovina ou Vacínia, não tão agressiva para esses animais, parecia conferir proteção contra a doença da Varíola Humana, geralmente fatal. O mesmo foi ainda o responsável por promover a inoculação da Varíola Bovina em seres humanos como forma de proteção aos mesmos contra essa patologia, denominando esse procedimento de Vacinação (Pinto et al., 2011). Esse termo é usado até hoje para representar a imunização dos organismos e conferir aos mesmos, proteção contra agentes infecciosos.

No ensino de Biologia, conteúdos relacionados à saúde apresentam uma variedade de temáticas a serem debatidas em sala de aula e são capazes de despertar grande interesse por parte dos alunos, em função da relação desses temas com a vivência e o cotidiano dos mesmos. Para Barreto e Teixeira (2013), os professores de Biologia são os responsáveis pela abordagem sobre a organização do corpo humano, seu funcionamento e de tudo que está relacionado ao mesmo, incluindo o seu comportamento e a interação destes com as doenças.

Nesse contexto, o estudo da Imunidade e da atuação do Sistema Imunológico (SI) na defesa do organismo, deve estar presente na disciplina de Biologia e ser trabalhado nesse nível de ensino da educação básica, pois entende-se, que a formação 
Research, Society and Development, v. 11, n. 2, e44211226020, 2022

(CC BY 4.0) | ISSN 2525-3409 | DOI: http://dx.doi.org/10.33448/rsd-v11i2.26020

conceitual e o estabelecimento de relações entre estes conceitos são pontos fundamentais para formação do indivíduo, posto que a ausência dessas informações incapacita e/ou dificulta a aprendizagem, a tomada de decisões e, dessa forma, o exercício pleno da cidadania (Chassot, 2006). Contudo, é necessário enfatizar, que a complexidade do assunto, o uso de nomenclaturas específicas e de difícil assimilação, além da pouca disponibilidade de recursos metodológicos que facilitem a compreensão do tema, são fatores limitantes para uma aprendizagem significativa.

Diante do exposto, torna-se possível levantar alguns questionamentos sobre: como trabalhar o conteúdo de Imunologia Básica nas aulas de Biologia do ensino médio? Que alternativas metodológicas facilitariam a compreensão sobre esse tema? De que forma as aulas poderiam se tornar mais atrativas aos alunos e promover uma aprendizagem efetiva dos mesmos? Essas indagações nos levam a pensar alternativas para serem trabalhadas em sala de aula, que vão ao encontro do pensamento de diversos pesquisadores e educadores que enfatizam a importância do lúdico na educação, como atividade necessária e colaborativa no processo de ensino e aprendizagem. Segundo Rau (2007) a palavra lúdico vem do latim ludus e significa brincar, estando inclusos nesse conceito os jogos, brinquedos e brincadeiras bem como todos os envolvidos nessas atividades.

De acordo com Conceição (2020) o jogo didático é um valioso recurso didático que pode unir questões lúdicas a momentos de interação e aprendizagem e a utilização de jogos educacionais como metodologia de ensino é capaz de despertar a curiosidade e o interesse dos discentes (Jesus, 2010). Estes aspectos contribuem para o aprendizado e de acordo com Kishimoto (2011) o uso de tais ferramentas como fins pedagógicos, nos leva para situações de ensino e aprendizagem, visto que o estudante aprende de forma prazerosa e participativa. Para Scaglia (2005), os jogos possuem um caráter de totalidade e complexidade quando inseridos em um ambiente que lhes pode ser favorável e apresentam-se como uma alternativa para se melhorar o desempenho dos alunos em alguns conteúdos considerados de difícil entendimento e/ou assimilação. O uso de jogos e de atividades lúdicas configuram-se então como uma excelente estratégia do professor para estimular as habilidades de seus discentes e dessa forma trabalhar aspectos cognitivos, afetivos, físico/motores, sociais, criativos e morais (Vieira, 2021). Através do brincar ou jogar os estudantes conseguem superar suas limitações e desenvolver uma melhor compreensão dos saberes. Nessa perspectiva, Antunes (2013) afirma que “o jogo, em seu sentido integral, é o mais eficiente meio estimulador das inteligências".

Nessa busca por alternativas relevantes ao ensino de Imunologia no ensino médio, entendendo que seu estudo no contexto escolar é, também, capaz de possibilitar aos discentes a construção de conhecimentos que resultem até mesmo em mudanças de atitude e decisões adequadas, tornando-os protagonistas da sua saúde e do seu bem-estar, que o presente trabalho se justificou pelo interesse em se produzir um material didático, na forma de um jogo de cartas de caráter lúdico, educativo e investigativo, denominado de IMUNOCARDS, capaz de permitir o reconhecimento das principais estruturas relacionadas ao Sistema Imunológico, bem como, a atividade de cada uma delas no que diz respeito as defesas do organismo para ser trabalhado por professores de Biologia em sala de aula durante a abordagem dessa temática.

\section{Metodologia}

Tratou-se de uma pesquisa exploratória e descritiva com base no método interpretativo, em consonância com a abordagem quali-quantitativa (Estela, 2018; Moreira \& Caleffe, 2006), que visou através da aplicação de questionários específicos para a tabulação dos dados e da elaboração e utilização de um jogo de cartas do tipo baralho, intitulado IMUNOCARDS, definir e ampliar os conhecimentos de estudantes do ensino médio da educação básica, sobre os conteúdos de Imunologia. A compilação dos resultados obtidos e a produção dos gráficos apresentados foram realizados através de planilhas do Microsoft Office Excel. 
O Trabalho foi desenvolvido no contexto de 02 (duas) turmas (D e E) de segundos anos do ensino médio, série em que se trabalha de acordo com a matriz curricular os assuntos de imunologia, do Colégio Estadual Governador Flávio Marcílio - COLFM (Figura 1), no município de Russas-CE, uma do turno manhã e outra do turno tarde, durante o segundo semestre do ano letivo 2019, atingindo um público alvo de cerca de 80 alunos regularmente matriculados nas mesmas, numa faixa etária compreendida entre 15 e 17 anos, independendo de sexo, cor/raça, etnia, religião, orientação sexual e identidade de gênero, classe ou grupo social.

A escola onde o estudo foi realizado está localizada na área urbana da cidade de Russas-CE, à Avenida Dom Lino, 725, Centro. Pertence a rede estadual de ensino, estando sob a abrangência da $10^{\circ}$ Coordenadoria Regional de Educação CREDE 10. A mesma oferta apenas o ensino regular, com um total aproximado de 1000 estudantes, oriundos de diversos bairros do município, bem como, da zona rural deste, distribuídos em 12 salas de aula nos turnos matutino e vespertino. A referida instituição conta ainda com Centro de Multimeios, Auditório, Laboratório Educacional de Ciências - LEC e Laboratório Educacional de Informática - LEI, tendo um quadro funcional de aproximadamente 60 colaboradores, entre funcionários de serviços, secretaria, professores e núcleo gestor.

A determinação do lócus do trabalho foi motivada pelo fato do autor desse projeto atuar como docente, da disciplina de Biologia, nesta instituição de ensino. O número de participantes do estudo correspondeu a $8 \%$ do total de alunos matriculados na escola (aproximadamente 1000 alunos) e a $25 \%$ do número de estudantes e de turmas do $2^{\circ}$ ano do ensino médio (em média 320 alunos e 08 turmas) da mesma, constituindo-se assim, índices representativos de uma amostra em pesquisa quali-quantitativa (Cordeiro \& Demétrio, 2007).

Para a obtenção dos resultados, num primeiro momento, foi observado e levado em consideração a percepção dos discentes a cerca dos conteúdos de Imunologia, esse levantamento, baseou-se na aplicação de um questionário estruturado, denominado de questionário 1 (Q1), na própria sala de aula (Figura 1), durante as aulas de Biologia, com duração média de 50 (cinquenta) minutos, compreendendo 01 (uma) hora/aula e que constou de 10 (dez) perguntas abertas relacionadas ao Sistema Imunológico e suas atividades nas defesas do organismo. Os dados aferidos resultantes dos questionamentos, foram agrupados de acordo com a semelhança das respostas apresentadas pelos educandos e tabulados em gráficos de porcentagens como análise qualitativa do estudo.

Figura 1: Local do estudo / Aplicação do questionário 1.

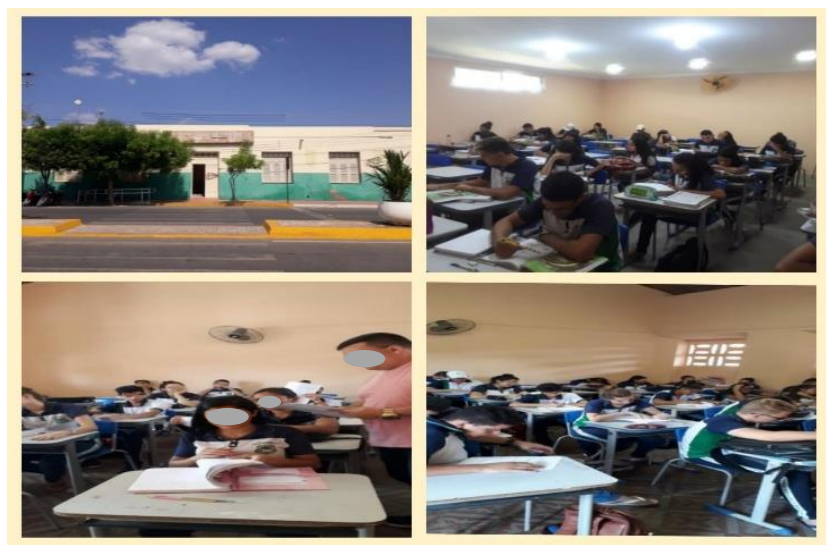

Fonte: Autoria Própria (2019).

$\mathrm{Na}$ aplicação desse questionário, os participantes foram identificados por meio de código alfanumérico, constando de letras maiúsculas, referente a turma a qual o mesmo fazia parte, seguida por números do alfabeto indo arábico que 
representaram a quantidade de discentes entrevistados (D1, D2, D3...). A medida supracitada visou assegurar o sigilo das informações a serem coletadas, assim como, o caráter de anonimato dos envolvidos na mesma.

Após a etapa inicial, foi realizada a abordagem do tema, através de aula expositiva dialogada, com o apoio do livro didático, envolvendo os discentes nas discussões, considerando as suas contribuições através dos conhecimentos prévios apresentados por estes e ampliando os conhecimentos dos mesmos a cerca do conteúdo proposto.

Nas aulas seguintes, foi trabalhado com os estudantes um método lúdico de aprendizagem (Figura 2), com a utilização de um jogo de cartas, produzido pelo autor/pesquisador com informações relevantes ao contexto da imunologia, cujas regras foram pré-definidas e repassadas aos alunos/jogadores na hora de sua aplicação, que também ocorreu no contexto de sala de aula, nas aulas de Biologia, com duração mínima de 100 (cem) minutos, compreendendo 02 (duas) horas/aula.

O jogo intitulado IMUNOCARDS, considerado de caráter educativo e investigativo, foi desenvolvido para ser trabalhado por professores de Biologia em sala de aula na abordagem do tema de Imunologia básica. O mesmo consta de um jogo de cartas do tipo baralho, confeccionado em papel couchê (offset) contendo 52 cartas dispostas aos pares, com informações relevantes sobre o conteúdo de Imunologia para o Ensino Médio (Figura 2). Tais informações foram agrupadas através do levantamento bibliográfico realizado pelo autor/pesquisador e podem ser complementadas durante o jogo pela interatividade que o mesmo dispõe, com o uso de leitor de QR CODE para acesso direto a internet através de links que levam a maiores informações a cerca dos conteúdos explorados nos cartões.

Figura 2: Logomarca e cartas do jogo / Aplicação do jogo.

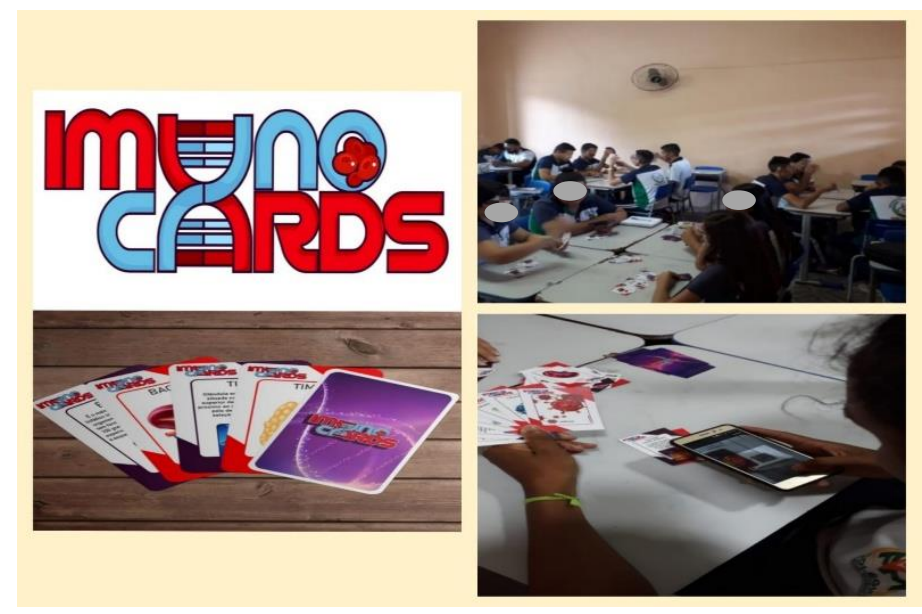

Fonte: Autoria Própria (2019).

Podem participar do jogo até 04 (quatro) jogadores a cada partida, recebendo cada um destes 08 (oito) cartas embaralhadas e que terão de formar, como objetivo do jogo, pares com as respectivas informações complementares. As demais cartas, que não foram distribuídas entre os participantes, ficam viradas sobre a mesa disponíveis para serem puxadas a cada rodada. As jogadas se dão em sentido horário, iniciando-se pelo jogador imediatamente a frente daquele que foi responsável por embaralhar e distribuir os cartões aos participantes. A cada rodada o jogador da vez terá de puxar uma carta e decidir por permanecer com a mesma ou descartá-la. Caso o jogador forme o par de cartas em sua jogada, o mesmo terá de baixar os cartões sobre a mesa e ler em voz alta o conteúdo destes, socializando as informações com os demais jogadores. Será considerado o jogador vencedor aquele que primeiro formar os 04 (quatro) pares correspondentes com as suas 08 (oito) cartas disponíveis. É permitido aos jogadores antecipar a sua jogada em caso de o descarte de um outro participante servir para que o mesmo possa formar o último par e vencer a partida. Em caso das cartas viradas e disponíveis para serem puxadas a cada 
rodada se esgotarem, aquelas que foram descartadas pelos participantes serão embaralhadas e viradas sobre a mesa para dar continuidade ao jogo até que se chegue a um vencedor.

Ao final, os alunos foram novamente submetidos a um questionário estruturado, denominado de questionário 2 (Q2), contendo 10 (dez) perguntas fechadas relacionadas a temática estudada, em sala de aula (Figura 3), com duração média de 50 (cinquenta) minutos, compreendendo 01 (uma) hora/aula, como forma de avaliação do projeto (análise quantitativa) sobre a contribuição do jogo didático para uma aprendizagem significativa, através do envolvimento dos estudantes na realização do mesmo como agentes ativos na aquisição dos conhecimentos. As etapas da coleta de dados do estudo estão dispostas de forma didática para melhor compreensão na Figura 3.

Figura 3: Aplicação do questionário 2 / Etapas da coleta de dados.

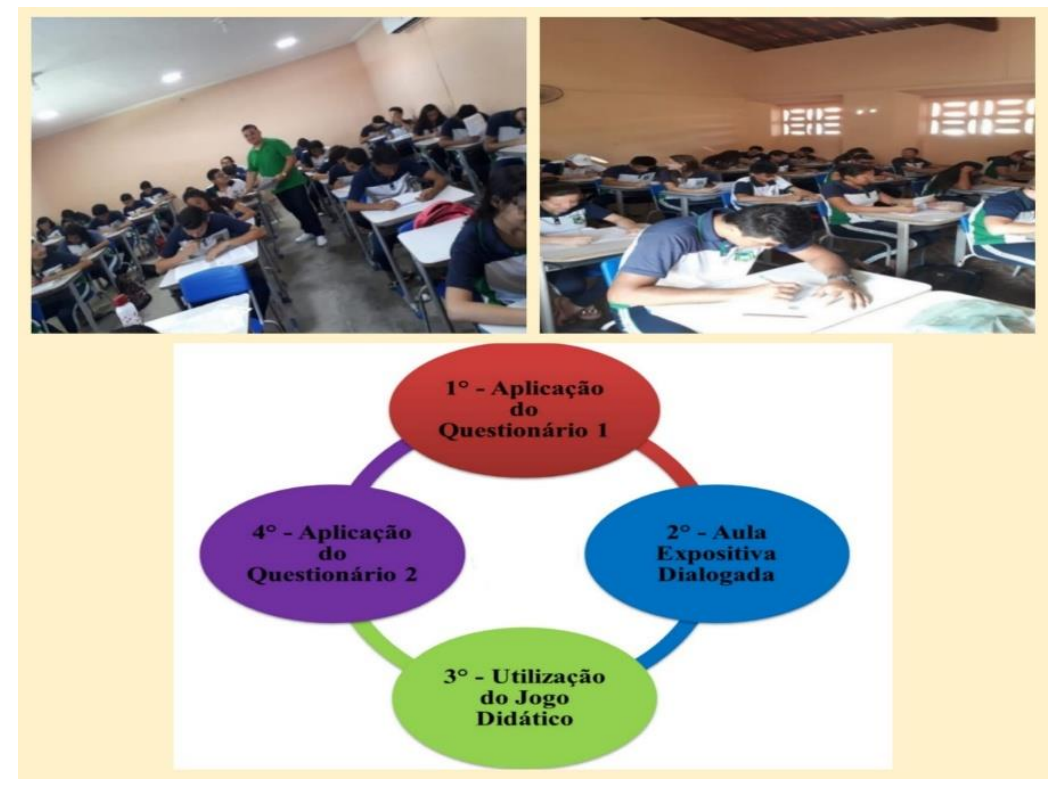

Fonte: Autoria Própria (2020).

\section{Resultados e Discussão}

Participaram efetivamente da pesquisa 78 alunos de 02 turmas (D e E) de segundos anos do ensino médio do Colégio Estadual Governador Flavio Marcilio no município de Russas-CE, que foram instrumentos ativos para a realização e obtenção dos resultados da mesma. A princípio os estudantes foram submetidos ao questionário 1 contendo perguntas discursivas relacionadas ao sistema imunológico e suas atividades nas defesas do organismo, como análise qualitativa da percepção dos discentes sobre o tema proposto.

Na primeira questão os participantes foram indagados sobre o que os mesmos entendiam por imunologia, tendo $39,7 \%$ destes considerado que imunologia corresponde ao estudo do sistema imunológico, 38,5\% ao estudo da imunidade, 10,2\% ao sistema de defesa pessoal do organismo, $3,8 \%$ ao sistema de proteção do corpo e $2,6 \%$ ao sistema que impede o organismo de contrair doenças, ao sistema que se relaciona ao sangue, na qual defende o corpo de qualquer patologia e ao estudo das doenças que podem afetar os organismos, respectivamente, estando dispostas algumas respostas abaixo e os resultados obtidos na Figura 4a.

D 9: "Imunologia é o estudo da imunidade, é através desse estudo que podemos nos certificar de como podemos nos prevenir de doenças;" " 
D 13: "É o sistema de defesa pessoal do corpo humano;"

$\boldsymbol{E}$ 4: "É o estudo do sistema imunológico, que é responsável pelas defesas do nosso organismo;"

Quando questionados sobre a relação da imunologia com a saúde humana, 55,2\% dos entrevistados afirmaram que essa relação baseia-se na proteção e no combate contra as doenças, $28,2 \%$ nas defesas do organismo, 10,2\% aos cuidados com a saúde e 6,4\% acreditam que essa relação ajuda a manter os organismos saudáveis (Figura 4b), conforme respostas em destaque.

D 12: "A Imunologia contribui para a saúde humana com a sua eficiência em produzir os glóbulos brancos, nossos protetores;"

E 2: "A imunidade ajuda a prevenir e combater doenças no nosso corpo para que não prejudique a nossa saúde;"

$\boldsymbol{E}$ 22: "O sistema imunológico é a principal defesa do nosso organismo, é ele que produz os anticorpos que atuam contra os invasores;"

Os alunos objetos do estudo também foram perguntados se de acordo com seus conhecimentos o sistema imunológico seria o responsável pelas defesas do nosso organismo, logo, a Figura $4 \mathrm{c}$ revela que 57,7\% admitiram que sim e justificaram que o sistema imunológico ajuda a combater e prevenir doenças, 29,5\% também afirmaram que sim, através da ação dos anticorpos e 12,8\% confirmaram a afirmativa ponderando que o sistema imunológico nos protege de microrganismos como vírus e bactérias. Abaixo estão descritas algumas dessas afirmações.

D 3: "Sim. O sistema imunológico apresenta vários glóbulos brancos que defendem o nosso organismo;"

E 29: "Sim. Através do sistema imunológico o corpo é capaz de produzir células que defendem o organismo humano;"

$\boldsymbol{E}$ 38: "Sim. Pois ele contém anticorpos que atuam na defesa do nosso organismo para combater vírus, bactérias e outros microrganismos;"

As respostas dadas pelos estudantes nos questionamentos apresentados foram ao encontro das afirmações de Abbas et al. (2015), que consideram o sistema imunológico como responsável pelas reações de defesa do organismo e que conferem aos mesmos resistência as doenças. Os educandos demonstraram uma formação conceitual bastante relevante, fundamental para o estabelecimento de relações entre estes conceitos e a aprendizagem, o que corrobora com os pensamentos de Chassot (2006).

Na questão seguinte os discentes puderam opinar sobre quais estruturas (células, tecidos, órgãos) do nosso organismo estariam relacionadas com o sistema imunológico, os mesmos podiam citar mais de uma opção de respostas, tendo sido observados os seguintes resultados (Figura 4d): 78,2\% consideraram o sangue como parte desse sistema, 47,7\% citaram os glóbulos brancos, $24,3 \%$ o coração, $12,8 \%$ os glóbulos vermelhos e as células, $10,2 \%$ as plaquetas, $5,1 \%$ o fígado, $3,8 \%$ as veias, as artérias e os anticorpos, respectivamente, 2,6\% disseram que a pele tem relação com o sistema imune e 1,3\% responderam que pulmão, medula óssea e os rins também estão relacionados ao mesmo. 
Figura 4a: Percepção dos estudantes - Questão 01.

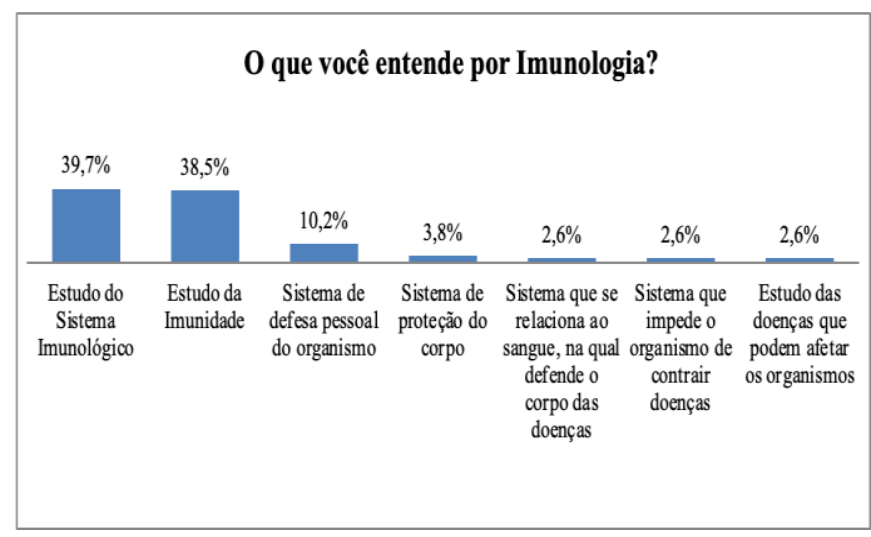

Figura 4c: Percepção dos estudantes - Questão 03

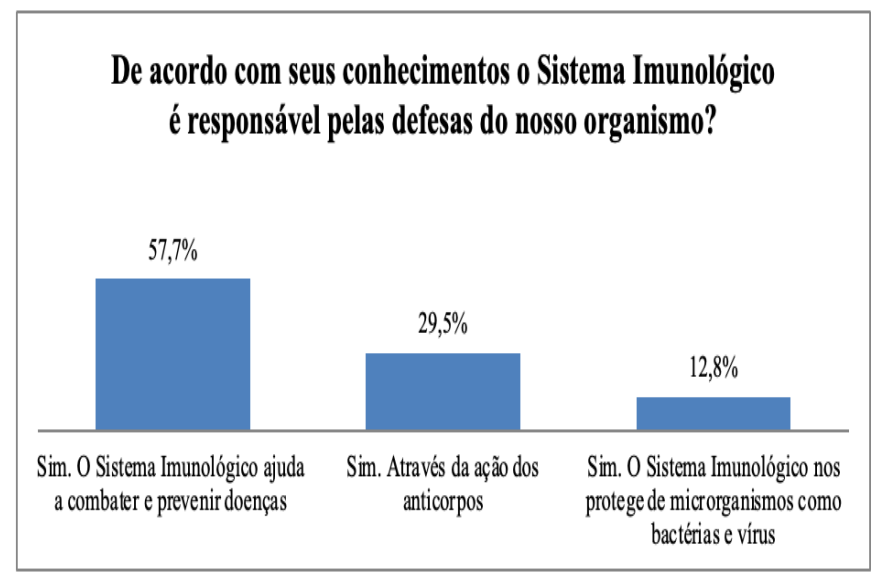

Figura 4b: Percepção dos estudantes - Questão 02.

\section{Qual a relação da Imunologia com a saúde humana?}

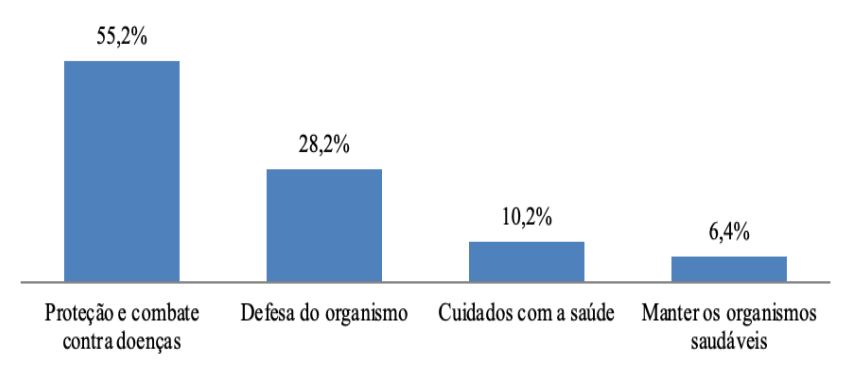

Figura 4d: Percepção dos estudantes - Questão 04

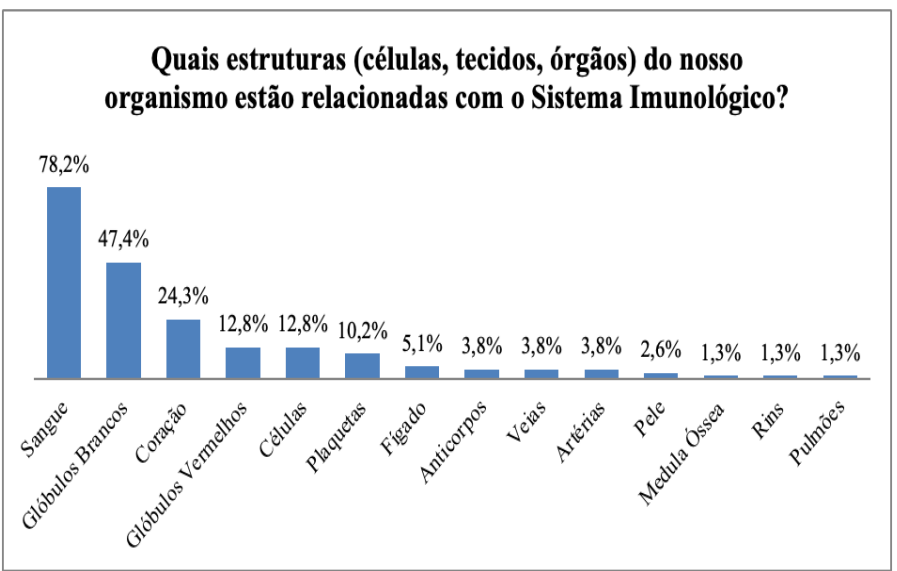

Fonte: Autoria Própria (2020).

A quinta questão, transcorreu sobre a ação do sistema imune na prevenção ou combate a doenças ocasionadas por quais agentes infecciosos? Na mesma os estudantes também podiam indicar mais de um agente como resposta (Figura 5a), logo, 83,3\% dos mesmos apontaram as Bactérias como principal patógeno dos organismos vivos, os Vírus foram citados por $67,9 \%$ dos entrevistados, seguidos por Protozoários (25,6\%), Fungos (21,8\%), Vermes (19,2\%) e outros microrganismos $(1,3 \%)$.

Como complemento da questão anterior, foi pedido no exercício seguinte exemplos de doenças conhecidas pelos alunos e que poderiam ser evitadas e/ou combatidas através da ação do sistema imunológico. Os dados obtidos e apresentados na Figura 5b, apontam que a gripe foi citada em $91 \%$ das respostas, tendo sido portanto a mais lembrada dentre todas as demais que se seguem, resfriado (17,9\%), dengue e demais viroses (11,5\%) cada, pneumonia (10,2\%), sarampo (7,7\%), tuberculose e sinusite $(5,1 \%)$ respectivamente, doenças renais e verminoses $(3,8 \%)$, câncer e febre amarela $(2,6 \%)$, além de caxumba, diarreia e Aids, que foram lembradas por 1,3\% dos entrevistados.

Os apontamentos dos estudantes nas questões mostradas, novamente se identificaram com as observações de Abbas et al. (2015), uma vez que os mesmos afirmam, que as células especializadas nas defesas dos organismos se encontram presentes principalmente na corrente sanguínea ou estão intimamente relacionadas a este tecido. Outro ponto de destaque, deve-se a percepção dos educandos quanto aos microrganismos presentes no meio e a capacidade dos mesmos de provocarem alguma desordem fisiológica em nosso corpo, logo, o reconhecimento de tais agentes infecciosos e das doenças ocasionadas por eles se 
mostra essencial para a manutenção da saúde e para uma melhor interpretação do mundo ao nosso redor, como afirma Andrade et al. (2015).

Os discentes também foram indagados se consideravam a existência de alguma relação entre as vacinas e o sistema imunológico? A Figura 5c, mostra que 30,8\% consideraram que sim, pois as vacinas são responsáveis por estimular a produção de anticorpos, 25,6\% também confirmaram a relação e sugeriram que as vacinas ajudam a fortalecer o sistema imunológico, $24,3 \%$ acreditam que as mesmas atuam no combate e prevenção das doenças, $16,7 \%$ disseram que estas apresentam os próprios microrganismos para que possamos criar imunidade e 2,6\% apontaram que as vacinas auxiliam na evolução das nossas células imunes. São observadas abaixo algumas dessas proposições.

D 17: "Sim. As vacinas auxiliam na evolução das células imunes;"

$D$ 26: "Sim. As vacinas oferecem imunidade contra as mais variadas doenças;"

E 31: "Sim; As vacinas já contém os próprios microrganismos para que possamos criar imunidade contra estes;"”

É importante enfatizar que a maioria dos participantes da pesquisa destacaram a estreita relação das vacinas com o sistema imunológico, mencionando as suas funções no organismo e conceituando-as de forma correta, dentro da perspectiva da presença de microrganismos modificados e enfraquecidos para ativar e fortalecer as células do sistema imune, fato corroborado por Tortora et al. (2017).

A indagação seguinte concentrou-se na opinião dos entrevistados quanto a se os bons hábitos e costumes associados a uma alimentação saudável e rica nos mais variados nutrientes seria capaz de contribuir para a eficiência do sistema imunológico, logo, $50 \%$ destes disseram que acreditavam que uma alimentação equilibrada e bons hábitos melhoram sim a imunidade do organismo, 26,9\% apontaram que uma vida saudável trás inúmeros benefícios para o corpo, 21,8\% afirmaram que bons hábitos e uma boa alimentação ajudam a combater as doenças, sendo que para 1,3\% dos pesquisados, não se faz necessário tais cuidados, mas sim o contato direto com "germes" e bactérias para criarmos os anticorpos. Abaixo estão representadas as falas de alguns dos estudantes, bem como, a apresentação dos dados na Figura 5d.

D 11: "Sim. Uma boa alimentação e bons hábitos ajudam a fortalecer o sistema imunológico e a combater as doenças;",

E 14: "Sim. Bons hábitos e uma alimentação saudável favorecem a imunidade do organismo;"

E 20: "Não. Pois precisamos ter contato com germes e bactérias para criarmos os anticorpos;" 
Figura 5a: Percepção dos estudantes - Questão 05

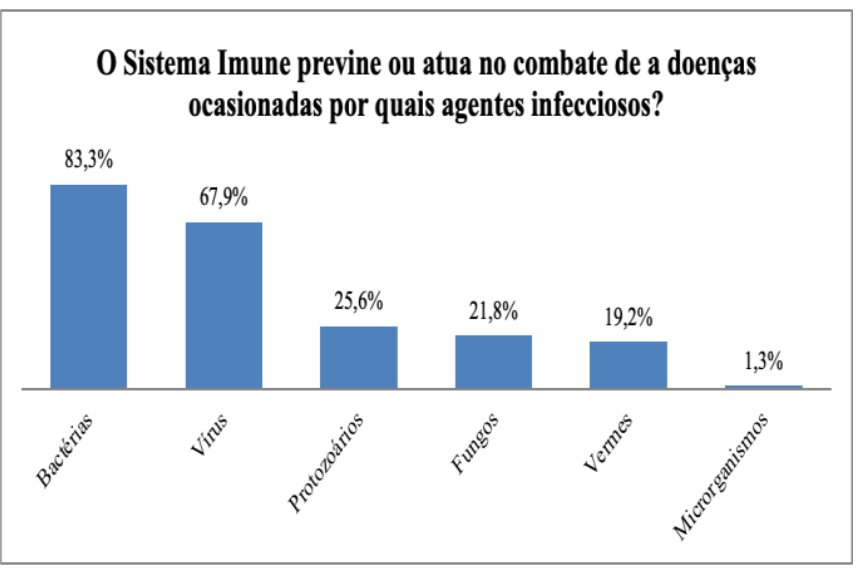

Figura 5c: Percepção dos estudantes - Questão 07

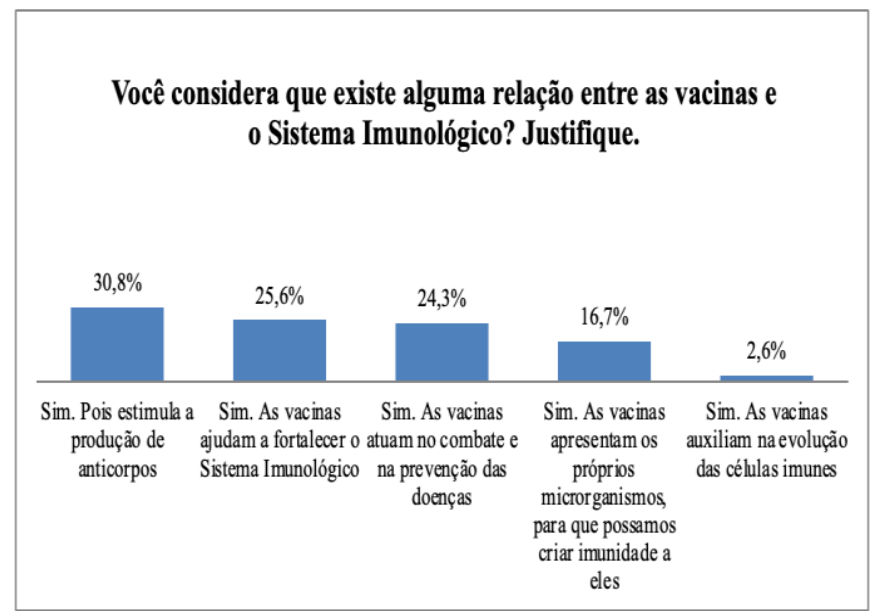

Figura 5b: Percepção dos estudantes - Questão 06

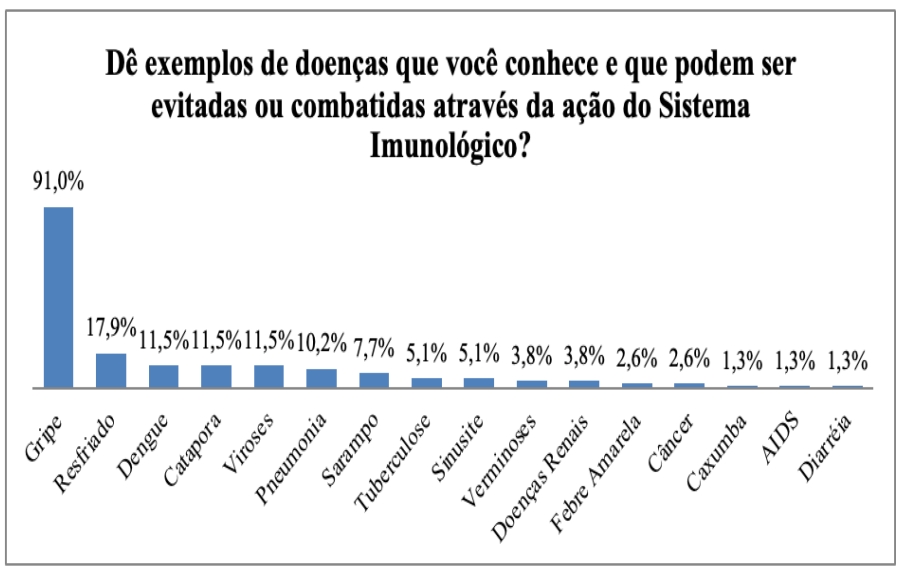

Figura 5d: Percepção dos estudantes - Questão 08

Fonte: Autoria Própria (2020).

De acordo com as observações feitas pelos alunos, deve-se ressaltar a importância de se incentivar os bons hábitos e costumes para uma vida saudável. Melo e colaboradores (2013), afirmam que informações sobre saúde devem partir de ações que valorizem o contexto e as experiências vividas pelos adolescentes, tendo na escola a parceria ideal na promoção desta. Adicionalmente, outros autores ressaltam que o contexto escolar representa um ambiente privilegiado para o desenvolvimento de estratégias capazes de transformar os jovens em adultos saudáveis e sensibilizados quanto às questões sobre sua saúde (Carvalho \& Araújo, 2012). Para Fernandes e Backes (2010), a articulação entre educação e saúde, promove um momento de reflexão crítica, autonomia cidadã e incentiva a adoção de uma postura que contribua nos cuidados com a mesma.

Na penúltima questão os discentes opinaram sobre a relevância do estudo da imunologia nas aulas de biologia do ensino médio, revelando através dos dados compilados na Figura 6a, que 33,3\% dos mesmos visualizaram o estudo como relevante para a aquisição de mais conhecimentos sobre o assunto em destaque, para 20,5\% esse estudo permite maiores informações sobre o sistema imunológico, 19,2\% disseram ter sido importante para compreender como o organismo reage ao ataque de agentes patológicos causadores de doenças, 9\% destacaram que o ensino da imunologia nas aulas de biologia melhora o entendimento do funcionamento do nosso corpo, bem como, o conhecimento das várias formas de imunização, respectivamente, tal estudo ajudaria ainda $5,1 \%$ dos participantes a saber como funcionam/atuam os anticorpos e $3,9 \%$ a entender as defesas naturais do corpo. 
As declarações dos estudantes se alinham aos pensamentos de Vaz (2011), por entender-se que o estudo da imunologia apresenta uma variedade de temáticas a serem debatidas, capazes de despertar grande interesse por parte dos alunos, em função da relação desses temas com a saúde, a vivência e o cotidiano dos mesmos. Logo, é papel do professor de Biologia, trabalhar esses conteúdos de forma sistematizada com enfoque no corpo humano, seu funcionamento e de tudo que está relacionado ao mesmo, incluindo o seu comportamento e a interação destes com o ambiente em que se encontram e com as doenças (Barreto \& Teixeira, 2013).

Abaixo estão destacadas na íntegra algumas das respostas obtidas.

D 4: "Esse estudo nos ajuda a entender sobre as defesas naturais do nosso corpo e o combate a várias doenças;" "

$D$ 23: "Através do estudo da imunologia podemos entender ainda mais sobre o nosso corpo, ajudando a termos cuidados com a nossa saúde;"

$\boldsymbol{E}$ 31: "Estudando a imunologia podemos compreender como o organismo reage ao ataque dos micro-organismos causadores de doenças;",

A décima questão transcorreu sobre que estratégias metodológicas poderiam contribuir para um melhor entendimento do conteúdo de imunologia nas aulas de biologia. Aos entrevistados foram pedidos exemplos de ações a serem desenvolvidas para melhor atender as suas expectativas e assim facilitar o processo de ensino e aprendizagem, os mesmos puderam apontar mais de uma estratégia como resposta. A Figura 6 b mostra que 69,2\% dos educandos observaram que o uso de jogos seria uma ferramenta importante para a aquisição dos conhecimentos, 44,9\% disseram que a utilização de vídeo aulas seria uma estratégia relevante, para $21,8 \%$ o uso de aplicativos colaboraria para uma aprendizagem significativa, 17,9\% citaram as mídias digitais como o uso dos slides, $14,1 \%$ optaram por aulas práticas no laboratório, 7,7\% destacaram a realização de gincanas, tendo o mesmo percentual dos estudantes sido favoráveis a realização de debates em sala de aula, 5,1\% opinaram por seminários e o uso da internet como ferramenta de pesquisa sobre os conteúdos, 2,6\% comentaram sobre o uso de mapas conceituais e documentários sobre o tema, respectivamente, 1,3\% viram nas aulas de campo uma metodologia a ser utilizada, tendo sido colocado ainda como sugestão o uso de um vocabulário menos formal e mais acessível aos mesmos, por 1,3\% dos questionados.

Figura 6a: Percepção dos estudantes - Questão 09.

Em sua opinião qual a relevância do estudo da Imunologia nas aulas de Biologia?

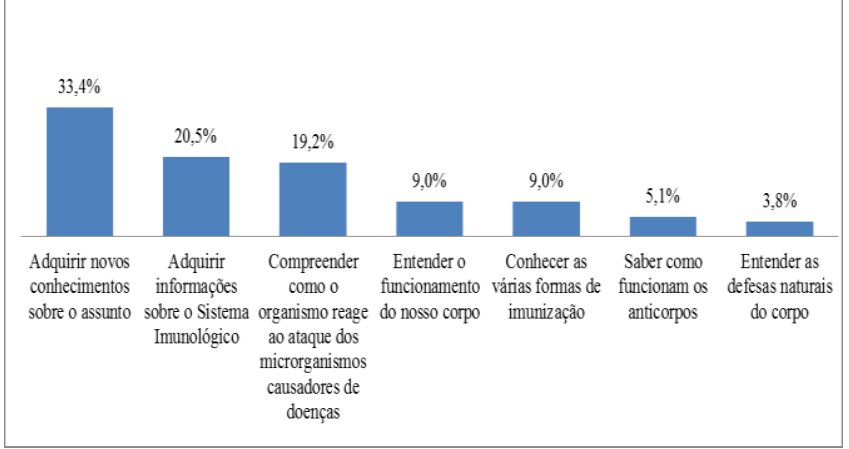

Figura 6b: Percepção dos estudantes - Questão 10.

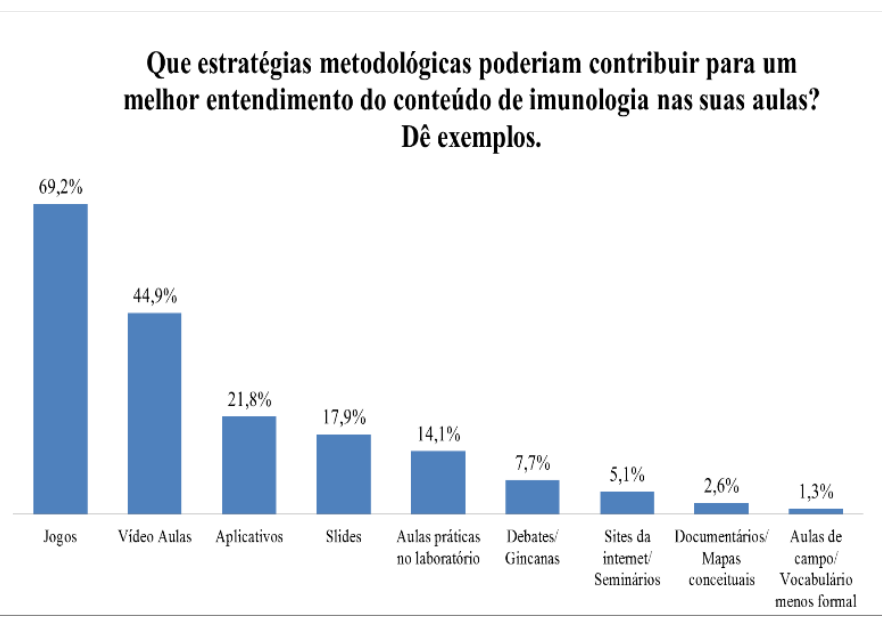

Fonte: Autoria Própria (2020).

É notório, que o modelo tradicional de aulas baseado apenas em lousa e livros ou textos avulsos não se sustenta numa sociedade na qual os sujeitos estão reinventando as formas de aprender/ensinar e se comunicar (Dantas, 2018). Nesse sentido, a 
Research, Society and Development, v. 11, n. 2, e44211226020, 2022

(CC BY 4.0) | ISSN 2525-3409 | DOI: http://dx.doi.org/10.33448/rsd-v11i2.26020

análise das proposições dos estudantes nos revelaram a fundamental importância da utilização pelos docentes de ferramentas alternativas de ensino, que possam possibilitar maior êxito na construção dos saberes, indo ao encontro com o que sugere Coelho e Viana (2011). Já Pliessnig e Kovaliczn (2008) reiteram que a utilização de metodologias diferenciadas torna esse processo mais interessante para o aluno, motivando-o a participar como protagonista, autor de seu próprio aprendizado. Oliveira (2015) discute em seu trabalho realizado com alunos do Ensino Médio da rede pública do município de Patos-PB, que cerca de $75 \%$ dos mesmos preferem aulas com o uso de metodologias, que tornem o ensino atrativo e de fácil assimilação. Os relatos dos participantes da pesquisa demonstraram total relação com os estudos de Jesus (2010), que visualiza a utilização de jogos educacionais como recurso de ensino capaz de despertar a curiosidade e o interesse dos discentes. Para Kishimoto (2011) o uso de jogos educativos como fins pedagógicos, nos levam para situações de ensino e aprendizagem, uma vez que, os alunos aprendem de forma prazerosa e participativa. Os jogos podem ser vistos ainda, como elementos facilitadores da assimilação de conceitos científicos, onde estes conduzem os alunos ao raciocínio, à reflexão, ao pensamento e, consequentemente, à construção do seu conhecimento (Santana, 2008).

A análise interpretativa dos dados qualitativos da pesquisa revelou uma boa percepção dos discentes acerca do tema imunologia, logo, os mesmos apresentaram conhecimentos prévios importantes para o bom entendimento do conteúdo nas aulas de Biologia.

Após as aulas expositivas acerca do tema proposto e a aplicação do jogo didático elaborado pelo autor/pesquisador, os estudantes foram novamente submetidos a um questionário 2, constando de 10 (dez) questões objetivas relacionadas a ferramenta metodológica utilizada, como análise quantitativa sobre e avaliação da eficácia do método lúdico no processo de ensino e aprendizagem dos mesmos.

Na primeira questão os participantes responderam se o jogo IMUNOCARDS apresentava conceitos, conteúdos ou temas estudados por eles, logo, 98,7\% dos entrevistados afirmaram que tinham esse conhecimento e 1,3\% disseram desconhecer tais informações. O questionamento seguinte pretendia saber se o jogo didático abordava conteúdos ou conceitos considerados de fácil ou difícil assimilação pelos educandos, 79,5\% consideraram o assunto facilmente assimilado, enquanto 20,5\% reconheceram as dificuldades do mesmo. A terceira questão indagava se a utilização da ferramenta IMUNOCARDS auxiliou na compreensão dos alunos sobre o tema proposto? Para 94,9\% destes o jogo contribuiu positivamente para a compreensão do assunto estudado, já os demais 5,1\% afirmaram não terem tido a contribuição do mesmo na aquisição de seus saberes. Os dados estão apresentados na Figura 7a.

As respostas obtidas demonstraram o conhecimento dos estudantes acerca do tema proposto, uma vez que este foi amplamente debatido com os mesmos. Os resultados apontaram um dado importante inerente ao estudo da Imunologia, logo, a maioria dos entrevistados consideraram que estes foram de fácil assimilação, contrastando com os pensamentos de Adnan (2009) que sugere que os conteúdos programáticos de Imunologia são reconhecidos como difíceis e complexos pelos alunos e pelos professores que os lecionam. Foi possível ainda, observar que no contexto escolar, a forma lúdica como, por exemplo, o uso de jogos que abordam os conteúdos associados à imunologia, despertam um maior interesse dos aprendizes e facilitam a compreensão do assunto, pois, uma exposição apenas teórica deste, em sala de aula, dificultaria o processo de ensino e aprendizagem (Almeida \& Santos, 2015). Fialho (2013), também confirma que os jogos com finalidades pedagógicas mostram a sua relevância, pois proporcionam situações que elevam a construção do conhecimento, introduzindo atividades lúdicas e prazerosas, potencializando a capacidade de interação e ação ativa e motivadora.

Quando questionados se a aplicação do jogo IMUNOCARDS em sala de aula teria facilitado a aquisição de informações e/ou conhecimentos sobre o tema em destaque, 94,9\% dos alunos afirmaram que o jogo facilitou a compreensão dos mesmos sobre o assunto abordado e 5,1\% disseram não considerar que este tenha contribuído para tal aquisição dos 
conhecimentos. No tocante a sua dinâmica de aplicação, 98,7\% dos entrevistados consideraram que a realização do jogo no contexto da sala de aula atendeu as expectativas, enquanto 1,3\% não foram favoráveis a utilização deste espaço como local de aplicação da ferramenta, conforme os resultados apontados na Figura $7 \mathrm{~b}$.

A utilização das tecnologias e de recursos metodológicos como os jogos, mostram-se fundamentais no ambiente escolar, pois esse é um local para a construção do conhecimento, para a socialização do saber, um local de discussão, de troca de experiências e desenvolvimento de uma nova sociedade (Mainart \& Santos, 2010).

Sobre se o uso do jogo possibilitou que os objetivos/finalidades propostos(as) para a aula fossem atingidos, 92,3\% interpretaram que sim, enquanto $7,7 \%$ consideraram que os objetivos não foram totalmente alcançados. Em relação ao tempo destinado para a aplicação do material lúdico, 92,3\% responderam que o mesmo foi satisfatório e suficiente para a realização da atividade, no entanto, 7,7\% entenderam que este não foi o adequado para a aplicação da ferramenta, de acordo com o que revela a Figura $7 \mathrm{c}$.

No oitavo questionamento os participantes da pesquisa puderam opinar sobre se a utilização do jogo IMUNOCARDS, se configurava como uma estratégia criativa. Os dados mostram que 100\% dos mesmos confirmaram essa afirmação, corroborando com a ideia de que a utilização de materiais potencialmente interessantes tem como consequência uma maior contribuição para a aprendizagem significativa dos discentes (Araújo \& Pedrosa, 2014). Kishimoto (2011), afirma que os jogos quando inseridos no contexto da sala de aula, auxiliam na compreensão dos conteúdos e são considerados ferramentas criativas, interativas e capazes de colaborar no processo de ensino e aprendizagem. Deste modo, a busca por inovações, tornam os conteúdos tradicionais mais atrativos, superando muitas dificuldades apresentadas na educação (Silva et al., 2016).

A questão seguinte, baseou-se na sondagem aos educandos sobre se o jogo seria agradável, atraente e/ou de caráter lúdico, logo, 98,7\% disseram se tratar de um recurso que envolvia todas essas características, enquanto 1,3\% discordaram dessa afirmação. As falas dos entrevistados corroboraram com o pensamento de Rau (2007) quanto ao aspecto de ludicidade dos jogos educacionais. O uso destes como atividades lúdicas, configuram-se como uma excelente estratégia para estimular as habilidades dos estudantes. Rosa (2012) afirma que através do brincar ou jogar os mesmos conseguem superar suas limitações e desenvolver uma melhor compreensão dos saberes. Além disso, trata-se de uma opção metodológica capaz de promover uma articulação mais significativa entre a(s) teoria(s) e a(s) prática(s), favorecendo a construção de uma autonomia pedagógica (Franco, 2016). Para Antunes (2013) “o jogo, em seu sentido integral, é o mais eficiente meio estimulador das inteligências.”

A última avaliação, visou averiguar dos discentes se houve dificuldades em utilizar ou compreender o jogo IMUNOCARDS e as suas regras, todavia, 84,6\% destes apontaram não ter tido quaisquer dificuldades com a utilização do mesmo, porém, para 15,4\% dos participantes estas existiram, podendo ou não ter comprometido a dinâmica de sua aplicação. Os apontamentos estão dispostos na Figura 7d. 
Figura 7a: Avaliação do jogo - Questões 01, 02 e 03.

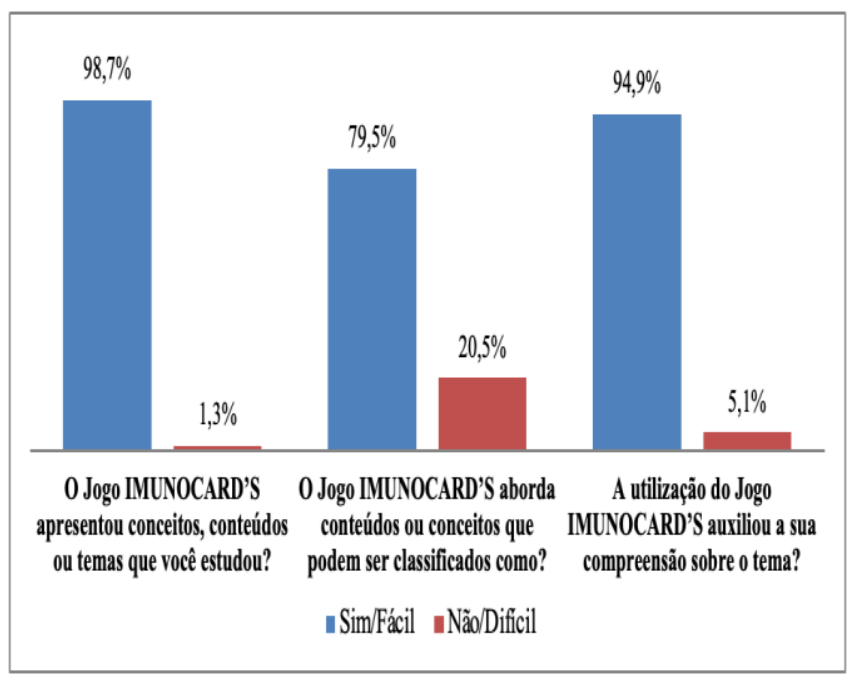

Figura 7c: Avaliação do jogo - Questões 06 e 07.

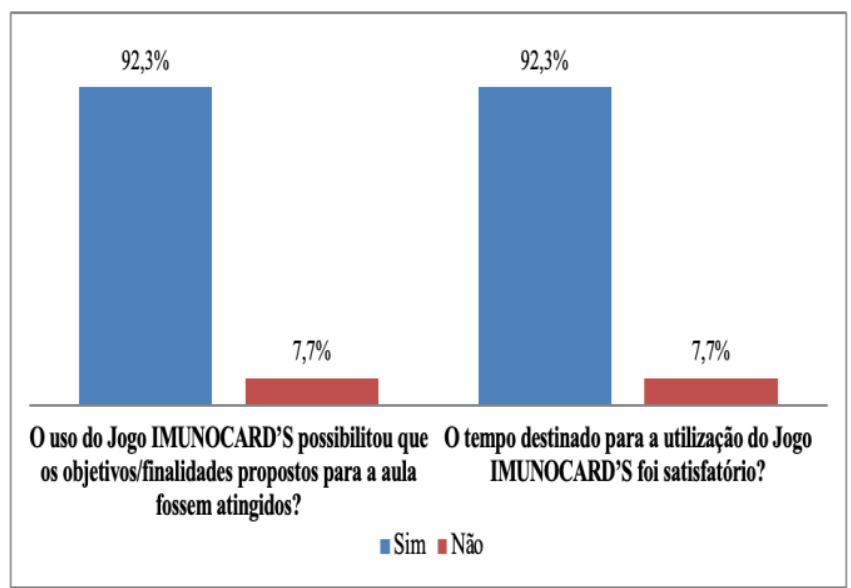

Figura 7b: Avaliação do jogo - Questões 04 e 05.

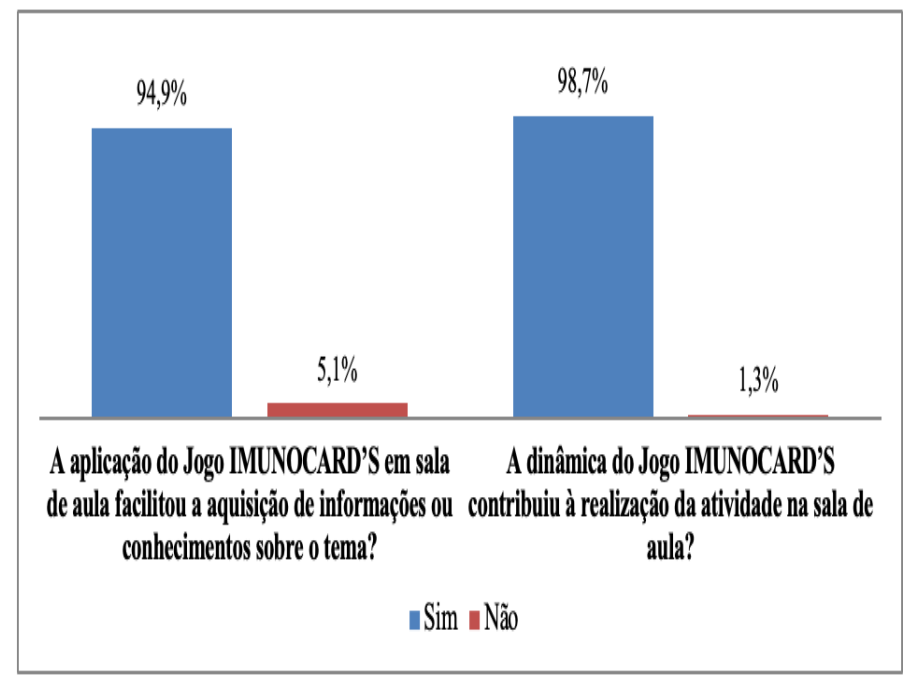

Figura 7d: Avaliação do jogo - Questões 08, 09 e 10.

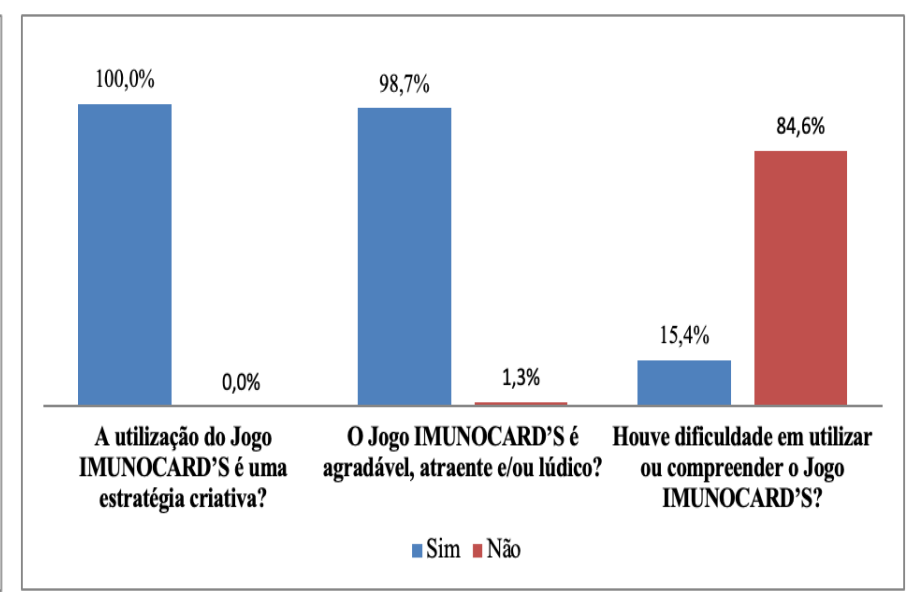

Fonte: Autoria Própria (2020).

A análise interpretativa dos dados quantitativos da pesquisa evidenciou que o jogo IMUNOCARDS apresentou conceitos e conteúdos de conhecimento dos estudantes e considerados de fácil assimilação pelos mesmos. A utilização desse método educativo auxiliou na compreensão destes acerca do estudo da imunologia, bem como, facilitou a aquisição de informações e conhecimentos sobre o tema proposto. Os dados apontaram ainda que o jogo se mostrou uma ferramenta criativa, agradável, atraente e lúdica, havendo pouca dificuldade por parte dos alunos para a sua utilização e/ou compreensão.

\section{Conclusões}

A pesquisa revelou uma boa percepção dos discentes acerca dos conteúdos de Imunologia, logo, os mesmos demonstraram conhecimentos prévios importantes para o entendimento do assunto nas aulas de Biologia. Foi produzido e aplicado aos estudantes um jogo de cartas físico, de valor acessível e com interação virtual sobre a(s) temática(s) de Imunologia, tendo o estudo do Sistema Imunológico se mostrado bastante relevante para a educação dos sujeitos envolvidos na pesquisa, pois agregou aos mesmos um conjunto de conhecimentos fundamentais para a compreensão da saúde e das relações estabelecidas entre o organismo e o meio em que vivem. O uso do jogo IMUNOCARDS como metodologia de ensino, foi capaz de despertar a curiosidade e o interesse dos educandos, o mesmo teve elevada aceitação dentre os alunos, e estes, 
Research, Society and Development, v. 11, n. 2, e44211226020, 2022

(CC BY 4.0) | ISSN 2525-3409 | DOI: http://dx.doi.org/10.33448/rsd-v11i2.26020

mediante a atividade, demonstraram melhor compreensão do tema proposto, em relação às aulas exclusivamente teóricas expositivas. O jogo IMUNOCARDS proporcionou um ensino de forma lúdica e motivadora para os adolescentes e favoreceu o protagonismo, a participação e a interação dos estudantes em sala de aula, contribuindo de forma direta para o processo de ensino e aprendizagem dos mesmos.

Neste sentido, visando sempre uma maior interação entre a teoria e a prática dos educandos nas aulas de Biologia, se faz cada vez mais necessário estudos relacionados as atividades docentes e a utilização de métodos lúdicos de aprendizagem como o jogo didático IMUNOCARDS, produto deste trabalho, permitindo assim uma verificação constante dos benefícios dessas metodologias de ensino e a sua contribuição para uma educação de qualidade. Como perspectivas futuras, a aplicação de outros recursos tecnológicos pode contribuir para deixar o jogo ainda mais dinâmico, acessível e é possível incorporar novos saberes ao mundo da Imunologia ao jogo, ou mesmo utilizar este modelo como referência para produzir outros jogos de áreas de conhecimento distintas.

\section{Agradecimentos}

À Coordenação de Aperfeiçoamento de Pessoal de Nível Superior - Brasil (CAPES), pelo apoio e financiamento do Programa de Mestrado Profissional em Ensino de Biologia - PROFBIO. À Universidade do Estado Rio Grande do Norte UERN pelo apoio Institucional e ao Colegiado do PROFBIO pelas contribuições.

\section{Referências}

Abbas, A. K., Litchtman, A. H., \& Pillai, S. (2015). Imunologia Celular e Molecular. Revinter.

Adnan, N. H., Yaacob, Y., Hassan, M. K., Salleh, H. M., \& Noorbatcha, I. A. (2009). Developing CAS models in immunology teaching.

Almeida, M. E. F., Santos, V. S. (2015). Ensino de Imunologia pela incorporação do conhecimento pelo teatro e a música. Revista de Ensino de Bioquímica, $13(3)$.

Andarde, V. A., Paula, L. M. Nicolini, L. B., Araújo, J. T. C., \& Coutinho Silva, R. (2015). A Imunologia no segundo segmento do Ensino Fundamental Brasileiro. Ciências \& Cognição, 20(1), 142-154.

Antunes, Celso. (2013). Jogos para estimulação das múltiplas inteligências. (19 ed.). Vozes.

Araújo, M. F. F., \& Pedrosa, M. A. (2014). Ensinar ciências na perspectiva da sustentabilidade: barreiras e dificuldades reveladas por professores de biologia em formação. Educar em Revista, 2(52), 305-318, Editora UFPR.

Barreto, C. M. B, \& Teixeira, G. A. P. B. (2013). Concepções prévias de universitários sobre o sistema imunológico. Rev. Bras. Ciên. Tecnol., 6(1).

Carvalho, A. M. C., \& Araújo, T. M. E. (2012). Conhecimento do adolescente sobre vacina no ambiente da Estratégia Saúde da Família. Revista Brasileira de Enfermagem, 65(2), 230-234.

Chassot, A. (2006). Alfabetização científica: questões e desafios para a educação. Editora UNIJUÍ.

Coelho, R. M. de F., \& Viana, M. da C. V. (2011). A utilização de filmes em sala de aula: um breve estudo no instituto de ciências exatas e biológicas da UFOP. Revista da Educação Matemática da UFOP, (1).

Conceição, A. R. da, Mota, M. D. A., \& Barguil, P. M. (2020). Jogos didáticos no ensino e na aprendizagem de Ciências e Biologia: concepções e práticas docentes. Research, Society and Development, 9(5), e165953290. https://doi.org/10.33448/rsd-v9i5.3290.

Cordeiro, G. M., \& Demétrio, C. G. B. (2007). Modelos Lineares Generalizados e Extensões. Minicurso 52a RBRAS e $12^{\circ}$ SEAGRO.

Dantas, R. R. (2018). A utilização de experimentos com materiais de baixo custo associados ao emprego de software no estudo de tópicos de Mecânica [dissertação]. Quixadá (CE): Universidade Estadual do Ceará - Faculdade de Educação, Ciências e Letras do Sertão Central.

Estrela, C. (2018). Metodologia Científica: Ciência, Ensino, Pesquisa. Editora Artes Médicas.

Fernandes, M. C. P., \& Backes, V. M. S. (2010). Educação em saúde: perspectivas de uma equipe da Estratégia Saúde da Família sob a óptica de Paulo Freire. Revista Brasileira de Enfermagem, 63(4), 568-569.

Fialho, N. N. (2013). Jogos no Ensino de Química e Biologia. Editora Inter Saberes. 
Research, Society and Development, v. 11, n. 2, e44211226020, 2022

(CC BY 4.0) | ISSN 2525-3409 | DOI: http://dx.doi.org/10.33448/rsd-v11i2.26020

Forte, W. C. N. (2011). Imunologia do básico ao aplicado. Artmed.

Franco, M. A. S. (2016). Pesquisa ação-pedagógica: práticas de empoderamento e participação. Educação Temática Digital, 18(2), 511-530.

Jesus, A. C. A. (2010). Como aplicar jogos e brincadeiras na educação infantil. Brasport.

Kisshimoto, T. M. (2011). Jogo, brinquedo, brincadeira e a Educação. (14a ed.), Cortez.

Mainart, D. A., \& Santos, C. M. (2010). A importância da tecnologia no processo ensino- aprendizagem. In: Congresso Virtual Brasileiro de Administração. Anais. http://www.convibra.com.br/upload/paper/adm/adm_1201.pdf.

Melo, M. C. P., Santos, M. M., Mendes, R. N. C., Sales, J. R. P., \& Silva, R. M. (2013). Percepção de adolescentes sobre imunização em uma escola pública de Petrolina - PE. Revista Mineira de Enfermagem, 17(2), 379-380.

Moreira, H., Caleffe, L. G. (2006). Metodologia da pesquisa para o professor pesquisador. DP\&A.

Murphy, K. (2014). Imunobiologia de Janeway. (8a ed.), Artmed.

Oliveira, B. I. N. (2015). Tecnologias aplicadas ao ensino de biologia: o uso dos Tablets em escolas estaduais do município de Patos-PB. Trabalho de Conclusão de Curso: Universidade Federal de Campina Grande, Centro de Saúde e Tecnologia Rural.

Pinto, E. F., Matta, N. E., \& Cruz, A. M. (2011). Vacinas: progressos e novos desafios para o controle de doenças imunopreveníveis. Acta Biológica Colombiana, 16(3), 197-212.

Pliessnig, A. F., \& Kovaliczn, R. A. (2008). O uso de metodologias alternativas como forma de superação da abordagem pedagógica tradicional na disciplina de biologia.

Rau, M. C. T. D. (2007). A ludicidade na educação: uma atitude pedagógica. Curitiba: Ibpex.

Rosa, A. B. (2012). Aula diferenciada e seus efeitos na aprendizagem dos alunos: o que os professores de biologia tem a dizer sobre isso? Monografia (Graduação em Ciências Biológicas) - Faculdade de Ciências Biológicas, Universidade Federal do Rio Grande do Sul, Porto Alegre.

Santana, E. M. (2008). A Influência de Atividades Lúdicas na Aprendizagem de Conceitos Químicos. In: Seminário Nacional de Educação Profissional e Tecnológica, (4). Belo Horizonte: Anais Eletrônicos, CEFET-MG.

Scaglia, A. (2005). O jogo dentro e fora da escola. Autores e Associados.

Silva, D. S. L., Santos, C. R., Santos, G. B., Alves, H. C. O., \& Oliveira, A. D. (2016). Desafios do ensino de Biologia. In: III CONEDU.

Tortora, G. J., Funke, B. R., \& Case, C. L. (2017). Aplicações Práticas da Imunologia. Microbiologia. (12a ed.). Artmed.

Vaz, N. M. (2011). Uma breve história da Imunologia. In Vaz, N. M., Mpodozis, J., Botelho J. F., Ramos, G. Onde está o organismo? 143-160. Editora UFSC.

Vieira, L. S., Docile, T. N., Vargas, A. B., Amoretty, P. R. de, Silveira-Alves, A., \& Figueiró, R. (2021). Proposta de um jogo didático para o ensino da conservação de recursos hídricos. Research, Society and Development, 10(7), e38010716645. https://doi.org/10.33448/rsd-v10i7.16645. 